\title{
REVIEW
}

\section{Treatment options for paediatric pulmonary arterial hypertension}

\author{
R.M.F. Berger* and D. Bonnet ${ }^{\#}$
}

ABSTRACT: Pulmonary arterial hypertension (PAH) is a serious, progressive condition, which can present idiopathically or secondary to conditions such as systemic sclerosis or congenital heart disease. The condition exists in both adult and paediatric forms, which possess several similar characteristics. Adult and paediatric PAH can, however, be distinguished based on underlying pathology and the presence of age-specific conditions, some of which are related to poor lung development in children. Improved knowledge of vascular biology has led to the development of several PAH-specific therapies, which have demonstrated clinical benefits in adults, including improved exercise capacity and prolonged survival. Treatment data in paediatric PAH are scarce. Although limited, the existing data indicate that current treatments for paediatric PAH are well tolerated and effective, at least in the short- and medium-term. Nevertheless, the current guidelines for clinicians, which recommend use of the adult treatment algorithm in paediatric patients, appear justified when judged according to the available evidence. However, further randomised, controlled trials are necessary to increase the evidence base for treatment of paediatric $\mathrm{PAH}$, especially in relation to age-specific conditions. At present, early initiation of treatment and combination pharmacological therapy may offer the most promising courses of action to improve outcomes in paediatric $\mathrm{PAH}$.

KEYWORDS: Children, paediatric, pulmonary arterial hypertension, treatment algorithm

$\mathbf{T}$ he characteristics of pulmonary arterial hypertension $(\mathrm{PAH})$ in the paediatric age group show both similarities and differences when compared with PAH in adults. On one hand, pulmonary vascular pathology in PAH, including medial hypertrophy, neointimal lesions and plexiform lesions, is similar in adults and children, although children have been suggested to present with more medial hypertrophy [1]. Also, vascular biology in PAH is believed to be defined by similar patterns of disturbed vascular and endothelial function in both age groups [2]. Haemodynamic alterations, including increased pulmonary arterial pressure and resistance, as per definition of the disease, are present in both children and adults, and dyspnoea at exertion is the most common clinical symptom in both populations [3, 4]. Heart failure with oedema seems to be less frequent in children, whereas syncope occurs more frequently in children with idiopathic PAH (IPAH) [3-5].

On the other hand, the distribution of underlying conditions in PAH differs between paediatric and adult populations. In children, $\mathrm{PAH}$ is associated with congenital heart disease (CHD) in $40-50 \%$ of patients, with diagnoses of IPAH or familial $\mathrm{PAH}$, now reclassified as heritable PAH (HPAH), being present in virtually all of the remainder [4, 6]. In addition, the types of CHD that occur in children in association with $\mathrm{PAH}$ are more heterogeneous than those observed in adults. $\mathrm{PAH}$ associated with connective tissue disease (CTD), HIV, portal hypertension or drugs/toxins do occur in children, but are extremely rare [4, 6].This is in contrast to adults with $\mathrm{PAH}$, in whom an association with CHD accounts for 11$20 \%$ of the population and IPAH/HPAH, CTD-, anorexigen-, portal hypertension- and HIV-associated PAH account for 43\%, 15\%, 10\%, 10\% and $6 \%$, respectively [7].

As childhood PAH is most commonly associated with $\mathrm{CHD}$, the majority of paediatric $\mathrm{PAH}$ patients are managed by paediatric cardiologists. In young children with CHD and unrestrictive shunts, where pulmonary blood flow is increased and pulmonary arterial pressure is elevated but pulmonary vascular resistance is low or mildly elevated, there exists early and reversible pulmonary

\section{AFFILIATIONS}

${ }^{*}$ Center for Congenital Heart

Diseases, Beatrix Children's Hospital University Medical Center Groningen, Groningen University Institute for Drug Exploration, University of Groningen, The Netherlands. "Paris Descartes University, Paris, France.

CORRESPONDENCE

R.M.F. Berger

Paediatric and Congenital Cardiology Beatrix Children's Hospital

University Medical Center Groningen P.0. Box 30001

9700 RB Groningen

The Netherlands

E-mail: r.m.f.berger@bkk.umcg.nl

Received:

Aug 312010

Accepted after revision:

Oct 112010

PROVENANCE

Publication of this peer-reviewed article was supported by Actelion Pharmaceuticals Ltd, Switzerland (unrestricted grant, European Respiratory Review issue 118). 
vascular disease. It is obvious that, in these patients, treatment of choice is surgical repair of the heart defect in order to normalise pulmonary arterial pressure, rather than treatment with $\mathrm{PAH}$ drugs. In other words, before embarking on pharmacotherapy, the first step in the treatment of children with CHD and pulmonary hypertension should be to assess the progression of pulmonary vascular disease and the possibility of surgical correction [8]. Conversely, patients with CHD associated with a left-to-right shunt, whose pulmonary vascular disease has already progressed to an advanced, irreversible stage, should not be considered for closure of the heart defect. In these patients, PAH may persist postoperatively and outcome may be worse than in patients with unrepaired PAH-CHD or Eisenmenger's syndrome [9]. It is these latter groups of PAH-CHD patients for whom $\mathrm{PAH}$ drug treatment options are applicable, and which are discussed in the current paper. Childhood PAH often presents with several unique, age-specific conditions, including bronchopulmonary dysplasia or congenital diaphragmatic hernia, both associated with disordered lung development. At present, the role of these conditions in pulmonary hypertension is poorly defined. Paediatric PAH has been frequently associated with chromosomal or syndromal abnormalities, most frequently trisomy 21, and with complex diagnosis due to multiple underlying conditions [4]. Persistent pulmonary hypertension of the newborn (PPHN), which occurs exclusively in the neonatal period, is also classified as PAH according to the Dana Point clinical classification of pulmonary hypertension [10]. However, the epidemiology, natural history, treatment and outcome of PPHN are sufficiently distinct from the chronic, progressive $\mathrm{PAH}$ seen in paediatric patients that we have excluded it from the present discussion [11]. Finally, untreated paediatric $\mathrm{PAH}$ has been reported to be associated with a median survival of 10 months, which is worse compared with adults (median untreated survival of $2.8 \mathrm{yrs}$ ) [12]. However, these unfavourable survival times for paediatric PAH have been challenged by recent data $[5,13]$.

In recent decades, increased knowledge of pulmonary vascular biology has led to novel therapies for PAH, which have demonstrated beneficial effects including increased exercise capacity, improved quality of life and prolonged survival. These effects have been demonstrated mainly in adults with PAH. Evidence-based treatment guidelines have subsequently been developed, based on continuously growing evidence derived from multiple clinical trials in adult PAH patients [14]. In contrast, very limited controlled data exist that report treatment responses in paediatric PAH.

In view of the foregoing considerations, the question arises as to whether paediatric and adult $\mathrm{PAH}$ should be treated according to the same treatment algorithms. The current guidelines recommend consideration of the same therapeutic algorithm for adults and children (fig. 1) [14]. This proposal is a class IIa recommendation ("the weight of evidence/opinion is in favour of usefulness/efficacy"), based on level of evidence C ("a consensus of opinion of the experts and/or small or retrospective studies [or] registries") [14].

In this paper, we will discuss the treatment algorithm for adult $\mathrm{PAH}$ as proposed by current guidelines, and summarise the available data concerning its use in paediatric PAH.

\section{GENERAL MEASURES AND SUPPORTIVE THERAPIES}

The general measures and supportive therapies proposed in the guidelines are mostly supported by class IIa recommendations (weight of opinion in favour of efficacy), based on level of evidence $C$ (consensus of expert opinion). The situation is similar for paediatric PAH [14].

\section{Oxygen administration}

One report on oxygen administration $\left(>12 \mathrm{~h} \cdot \mathrm{day}^{-1}\right)$ in children with $\mathrm{PAH}$, mainly PAH-CHD, suggested a beneficial effect on survival [15], whereas no beneficial effects of nocturnal oxygen administration could be demonstrated in adult patients with PAHCHD [16]. In general, an improved level of subjective well-being experienced by a subgroup of patients with some degree of hypoxaemia may be the main indication for oxygen administration.

\section{Anticoagulant therapy}

The use of anticoagulant therapy in PAH is based on the concept of a prothrombotic microenvironment and the finding of (micro)thrombi in the pulmonary vasculature of patients with $\mathrm{PAH}$, and is supported by observational data from adults with mainly IPAH/HPAH $[17,18]$. However, the potential benefits of oral anticoagulant therapy should be weighed against risks in specific patient groups, such as, for example, haemoptysis and a general bleeding tendency in patients with Eisenmenger's syndrome [19-21]. The use of anticoagulant therapy in children with PAH is increasingly recommended, especially in conditions such as hypercoagulability, and overt heart failure, and where there is an indwelling central venous line, although no data are available on the efficacy and risk/ benefit ratio of oral anticoagulation in children with PAH [18, 22]. Anticoagulant therapy in young children may be accompanied by age-specific problems of administration, response and dosing [23]. Therapy with anticoagulants should, therefore, be considered on an individual patient basis.

\section{Infection prevention}

Although no controlled data exist, vaccination against influenza and pneumococcal disease is recommended in $\mathrm{PAH}$ patients [14]. In children, additional infection prevention in specific age groups should be considered, such as respiratory syncytial virus prophylaxis in infants with PAH [24, 25].

\section{CALCIUM-CHANNEL BLOCKERS}

Uncontrolled, open-label, prospective, observational studies have reported improved haemodynamics and survival with long-term calcium-channel blocker therapy in both adult and paediatric patients with IPAH/HPAH, provided they responded to acute vasodilator testing at initiation of therapy $[26,27]$. Unfortunately, however, acute responders comprise less than $10 \%$ of adult patients with IPAH. In children, the proportion of acute responders has been suggested to be higher, although this difference may be due to disparate criteria used to identify responders. The "Sitbon criteria" for acute responders in adult IPAH, now generally used, have not been studied in paediatric PAH [28]. Vigilance is necessary, since a significant number of patients lose their initial responsiveness, sometimes within $1 \mathrm{yr}$, a situation that precedes deterioration of disease. In these patients, the treatment strategy must be adapted to include specific, PAH-targeted therapy, as is the case with PAH patients who showed no acute, initial response to vasodilator testing. 


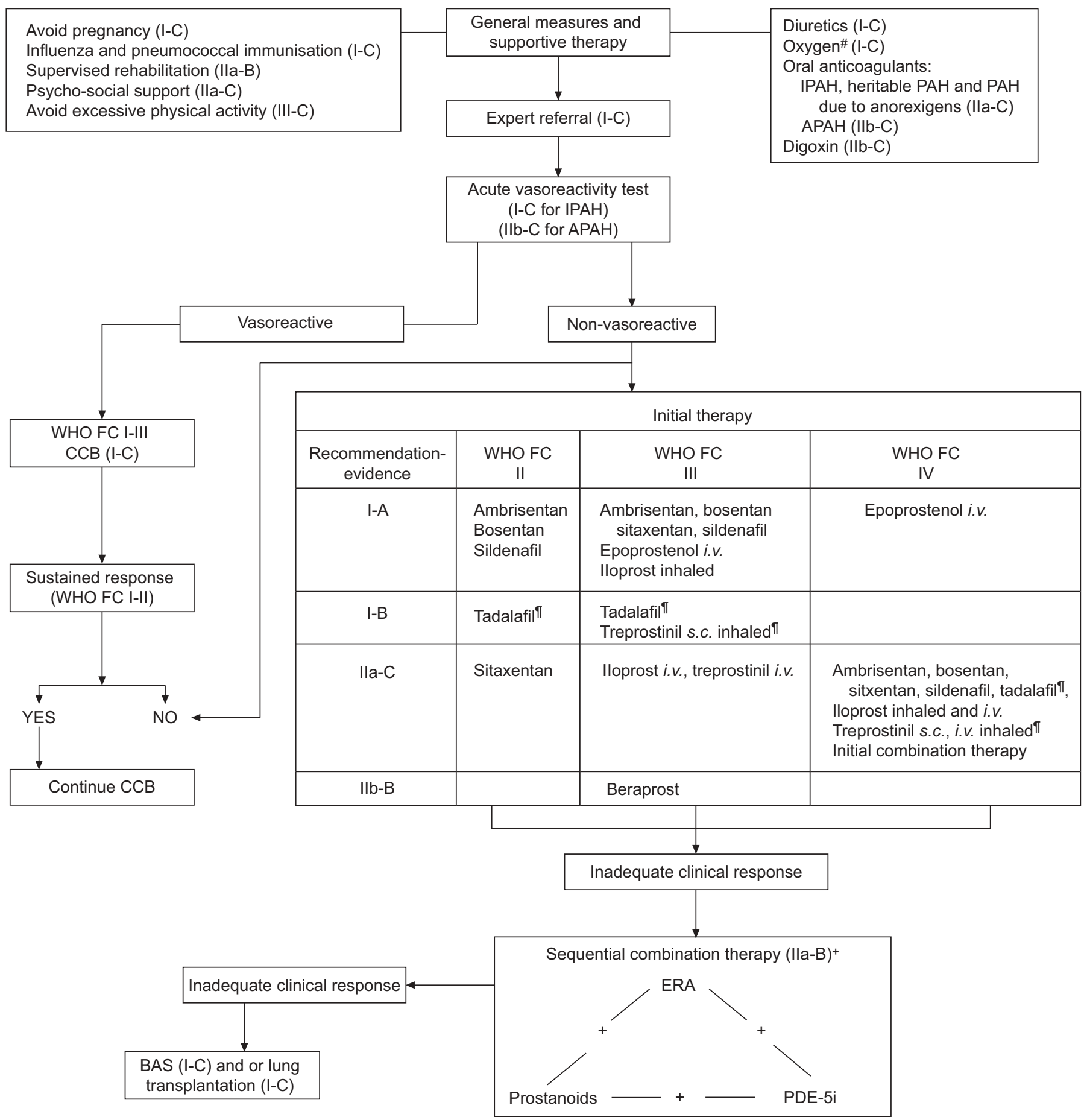

FIGURE 1. Evidence based-algorithm for patients with pulmonary arterial hypertension (PAH). IPAH: idiopathic PAH; APAH: associated PAH; WHO FC: World Health Organization functional class; CCB: calcium-channel blocker; ERA: endothelin-receptor antagonist; PDE-5i: phosphodiesterase type-5 inhibitor; BAS: balloon atrial

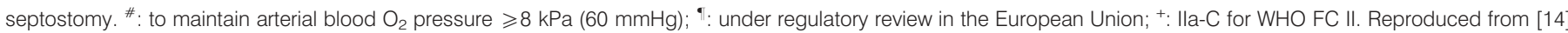
with permission from the publisher.

\section{PROSTANOIDS}

Prostacyclin is an endogenous, potent pulmonary and systemic vasodilator, with antimitogenic properties and antiplatelet activity. Reduced expression of prostacyclin synthetase in pulmonary endothelium and an imbalance between the thromboxane and prostacyclin metabolites have been observed in patients with PAH [29, 30].

\section{Epoprostenol}

The prostacyclin analogue epoprostenol has a very short halflife of 3-6 min, and so must be administered continuously through a permanent intravenous catheter. Its use is recommended as first-line treatment in patients with severe $\mathrm{PAH}$ in World Health Organization (WHO) functional class (FC) IV 
(level of evidence A) (fig. 1) [14]. This indication is similar in adults and children with IPAH, and is based on observational data showing continuous i.v. epoprostenol to be equally effective in children and adults for improving symptoms, haemodynamics and survival [27, 31]. LAMMERs et al. [32] recently confirmed these data in children with IPAH, and demonstrated similar results in children with $\mathrm{PAH}-\mathrm{CHD}$ treated with i.v. epoprostenol.

The long-term persistence of these beneficial effects, as reported by YUNG et al. [33], who showed a 10-yr survival of $61 \%$ in IPAH patients, indicates that the use of epoprostenol in children is justified despite the invasive nature of its delivery system and its risk for associated complications, such as thromboembolic events, line sepsis, local infection or catheter displacement. In patients with PAH-CHD and right-to-left shunting, the additional risks of such complications, which also include cerebral emboli or abscesses, must be weighed against the expected therapeutic benefits on an individual basis.

Side-effects of epoprostenol, which include facial flushing, headache, nausea, jaw pain, abdominal cramping and diarrhoea, are transient, occur at similar rates in children and adults and are often related to initiation of therapy or dose increments. Clinical observations from centres experienced in the treatment of both adult and paediatric $\mathrm{PAH}$ patients suggest that optimal dosing in children is higher than in adults, although objective supporting data are missing. More stable analogues of prostacyclin have been developed that allow for less invasive routes of administration. Clinical efficacy of these analogues has been demonstrated in adults, whether administered intravenously (iloprost, treprostinil), subcutaneously (treprostinil), by inhalation (iloprost, treprostinil) or orally (beraprost), and these agents are recommended with varying levels of evidence for patients in WHO FC III (fig. 1) [14]. However, data on the use of these analogues in children are scarce.

\section{Treprostinil}

Treprostinil sodium, a prostacyclin analogue with an elimination half-life of $4-5 \mathrm{~h}$, allows for i.v. or s.c. administration [34] or inhalation [35]. Several studies that included both older children and adults demonstrated or suggested efficacy of treprostinil i.v. or s.c. in different forms of PAH [36-38]. However, the proportions of children included in these studies were very small $(<5 \%)$, and the paediatric results were not analysed separately. Side-effects, in addition to the prostanoidspecific facial flushing, headache, jaw pain and diarrhoea, are dominated by pain at the subcutaneous infusion site. This clinically important side-effect has largely precluded its use in children.

Recently, small, uncontrolled reports provide preliminary evidence that selected children with PAH can safely be switched to s.c. treprostinil from oral therapy in case of clinical deterioration [39], or as an alternative to IV epoprostenol [40]. Recently, add-on therapy with inhaled treprostinil in adult PAH patients already using either bosentan or sildenafil was shown to be effective [41], but no paediatric data are available. Finally, treprostinil for oral administration, an attractive option for children, is under development.

\section{Iloprost}

Iloprost is a stable analogue of prostacyclin with a biological half-life of 20-30 $\mathrm{min}$ [42]. The use of i.v. iloprost, although widespread in some countries, has never been studied in a randomised, controlled trial. Inhaled iloprost has been demonstrated to improve functional class and 6-min walk distance in adult patients with PAH or inoperable chronic thromboembolic pulmonary hypertension [43]. However, haemodynamics were improved only when measured directly after inhalation, while trough values after 12 weeks were similar to baseline. Patients have to inhale the drug not less than six to nine times per day, which poses practical limitations, especially in children.

Data in children are limited. Recently, Ivy et al. [44] reported safety and efficacy data in paediatric patients with PAH. Inhaled iloprost caused sustained functional improvement in some children with $\mathrm{PAH}$, and patients could be transitioned from i.v. to inhaled prostanoid therapy. However, inhaled iloprost occasionally induced bronchoconstriction. The authors concluded that clinical deterioration, side-effects and poor compliance owing to the frequency of administration could limit chronic treatment in children [44]. Additionally, inhaled iloprost was shown to be equally effective as inhaled nitric oxide for lowering mean pulmonary artery pressure and pulmonary vascular resistance index, which may indicate a use for these acute haemodynamic effects of inhaled iloprost in a critical care setting.

\section{Oral beraprost}

Beraprost sodium is a stable prostacyclin analogue with a halflife of $1-2 \mathrm{~h}$, which allows for oral administration. Two randomised, controlled studies with beraprost have shown improvement of exercise capacity in adults with $\mathrm{PAH}$ after 3 months and 6 months, but not at either 9 months or 12 months $[45,46]$. Therefore, the use of beraprost in PAH is no longer recommended by most experts. Adequate data concerning the clinical effect of beraprost in children with PAH are not available.

\section{ENDOTHELIN-RECEPTOR ANTAGONISTS}

The endothelin (ET) system is activated in the different forms of PAH. ET-1 is a potent endogenous vasoconstrictor with mitogenic properties that it exerts through two receptor subtypes: $\mathrm{ET}_{\mathrm{A}}$ receptors are localised to vascular smooth muscle cells and fibroblasts, whereas $\mathrm{ET}_{\mathrm{B}}$ receptors are predominantly localised to pulmonary endothelial cells and, to a lesser extent, vascular smooth muscle cells. The $\mathrm{ET}_{\mathrm{B}}$ receptors are involved in ET-1 clearance, and activation induces the release of vasodilatory and antiproliferative substances, such as nitric oxide. Dimerisation theory suggests that $\mathrm{ET}_{\mathrm{B}}$ receptors expressed on vascular smooth muscle cells have the ability to couple with $\mathrm{ET}_{\mathrm{A}}$ receptors, and may subsequently adopt the function of the latter and mediate vasoconstriction [47]. Despite the differences in receptor isoform activity, both dual $\mathrm{ET}_{\mathrm{A}}-\mathrm{ET}_{\mathrm{B}}$-receptor antagonists (bosentan) and selective $\mathrm{ET}_{\mathrm{A}}$-receptor antagonists (sitasextan and ambrisentan) have demonstrated similar effectiveness in adult patients with $\mathrm{PAH}$, improving haemodynamics, exercise capacity and WHO FC. ET-receptor antagonists (ERAs) are recommended as potential first-line treatment for WHO FC II/ III PAH patients, with evidence mostly at level A. Their use in 
FC IV PAH patients is supported by a class IIa recommendation, level of evidence C (fig. 1) [14].

\section{Bosentan}

Bosentan is an oral, dual ERA that has been demonstrated to improve haemodynamics, exercise capacity, time to clinical worsening and WHO FC in adults with PAH [48-50] and haemodynamics, exercise capacity and WHO FC in those with Eisenmenger's physiology [51, 52].

Although no randomised, controlled trial has yet been performed in children with $\mathrm{PAH}$, open-label controlled and uncontrolled studies in children demonstrate improvements in haemodynamic measurements, exercise capacity or WHO FC with bosentan therapy, either as monotherapy or in combination with other PAH therapies [53-57]. Pharmacokinetics, safety and efficacy of bosentan in paediatric patients have also been studied, the results demonstrating lower bosentan exposure in paediatric patients compared to adult patients, despite increased doses [53, 54]. Bosentan was well tolerated and improved pulmonary haemodynamics after 12 weeks.

ROSENZWEIG et al. [55] described the long-term outcome of children with PAH treated with bosentan, with or without concomitant prostanoid therapy. Their results suggested improvement in pulmonary haemodynamics after a mean follow-up of 9 months, with 1- and 2-yr survival rates of $98 \%$ and $91 \%$, respectively. In an open-label study, VAN LOON et al. [57] compared the effects of bosentan in 10 children versus 20 adults with PAH associated with systemic-to-pulmonary shunts, who were predominantly on bosentan monotherapy. Their data indicated that the initial improvement in exercise capacity in both adults and children progressively declined at longer-term follow-up, a deterioration that was more pronounced in the paediatric patients.

Current data suggest that the safety profile of bosentan is comparable between adults and children, with the type and incidence of reported side-effects being similar [6, 54]. The potential exception is elevated transaminase levels, which occur in children but less frequently than in adults $(2.7 \%$ versus $7.8 \%$, respectively), according to the European bosentan postmarketing surveillance programme [6]. Recently, a paediatric dispersible tablet formulation of bosentan has become available in the European Union (EU) only for children $>2$ yrs of age, allowing further optimisation of the dose for young children [54].

\section{Sitaxentan}

Sitaxentan, an oral, highly selective $\mathrm{ET}_{\mathrm{A}}$-receptor antagonist approved for use in the EU, Canada and Australia, has been demonstrated to improve exercise capacity and haemodynamics in patients older than 16 yrs of age with $\mathrm{PAH}$, including IPAH, PAH-CTD and PAH-CHD [58, 59]. An open-label study has demonstrated the persistence of this effect over time [60]. However, no specified data from the limited subgroup of patients with PAH-CHD in these studies have been published. Data in younger children are very limited [61].

\section{Ambrisentan}

Ambrisentan, an oral, selective $\mathrm{ET}_{\mathrm{A}}$-receptor antagonist, has been demonstrated to improve exercise capacity, haemodynamics and time to clinical worsening in adults with PAH $[62,63]$.
Ambrisentan is well tolerated and associated with an apparent lower risk of transaminase elevation and suggested to have a lower drug interaction than other agents in the same class [14]. A controlled, open-label study investigating pharmacokinetics, tolerability, safety and efficacy of ambrisentan in paediatric $\mathrm{PAH}$ has been initiated, but no data are currently available.

\section{PHOSPHODIESTERASE-5 INHIBITORS}

Inhibition of phosphodiesterase type 5 (PDE5) induces vasodilation through the nitric oxide/cyclic guanosine monophosphate pathway, and also exerts antiproliferative effects $[64,65]$. Inhibitors of PDE5, such as sildenafil or tadalafil, have been evaluated in adults with $\mathrm{PAH}$, and were demonstrated to improve haemodynamics, exercise capacity and WHO FC in patients with IPAH, PAH-CTD or PAH-CHD after 12 weeks of treatment $[66,67]$. Sildenafil and tadalafil are recommended for first-line treatment of patients with $\mathrm{PAH}$, supported by levels of evidence A and B, respectively (fig. 1) [14].

\section{Sildenafil}

Open-label observational studies in children with various types of progressive PAH suggest a similar effect of sildenafil on haemodynamics and exercise capacity at 1-yr follow-up [68]. Sildenafil therapy was well tolerated and no significant adverse effects were observed. Data recently presented at the 2009 European Respiratory Society congress from a randomised, placebo-controlled, dose-ranging study confirm the safety and tolerability of sildenafil therapy in paediatric patients with IPAH/HPAH and PAH-CHD [69]. Furthermore a near-significant trend was observed for the increase in maximal oxygen uptake in a subgroup of patients that could perform a reliable exercise test. These data, which are yet to be published in full, generally support the efficacy of sildenafil in paediatric PAH.

In a critical care setting, sildenafil has been demonstrated to be an equally effective pulmonary vasodilator as inhaled nitric oxide, with potential application to augment the pulmonary vasodilatory action of nitric oxide inhalation and to facilitate nitric oxide withdrawal. However, these effects came at the potential cost of systemic hypotension, increased pulmonary shunting and impaired oxygenation [70, 71].

An intravenous form of sildenafil has recently been approved for use in the USA and EU, the obvious application of which is in situations where enteral use is not possible.

\section{Tadalafil}

Tadalafil is a selective PDE5 inhibitor that can be administered once daily. Its beneficial effects in $\mathrm{PAH}$, consisting of improved exercise capacity, haemodynamics and time to clinical worsening, have been demonstrated in adults [67]. However, data in children are not available.

\section{COMBINATION THERAPY}

Available data on the previously described, targeted $\mathrm{PAH}$ therapies suggest that they are generally effective, well tolerated and safe in both children and adults. These therapies target different pathways involved in the pathophysiology of PAH. Combination therapy is an attractive concept, as by acting on multiple pathways simultaneously, they may be 
more effective than targeting just one pathway. The treatment algorithm recommends combination therapy, however, without specifying which combination should be used (class IIa recommendation/level of evidence B) (fig. 1) [14].

Data are available from adult patients on the additional value of combining targeted PAH treatments, mostly relating to addon therapy. For example, bosentan added to i.v. epoprostenol background therapy [72], sildenafil added to i.v. epoprostenol [73] and inhaled treprostinil added to either bosentan [41, 74] or sildenafil [41] have been studied, with the results indicating additional beneficial effects for the combination.

The optimal timing of combination therapy remains unclear, but HOEPER et al. [75] developed a treatment algorithm based on the concept of "goal-oriented treatment". Applying their goal-oriented treatment algorithm to the decision-making of the authors [75] led to improved survival in their centre. Whether or not these results are applicable to infants and children with $\mathrm{PAH}$ remains unclear. Recently published data on paediatric $\mathrm{PAH}$ in the current era of targeted $\mathrm{PAH}$ treatments demonstrated improved survival with these therapies, compared with predicted survival values [13]. However, this improvement appeared to be driven by patients who were diagnosed before the new therapies were available, while improved survival was not achieved in newly diagnosed children (fig. 2) [13]. These findings suggest that optimisation of therapy is required, possibly through more aggressive therapy and earlier initiation of combination therapy.

\section{FUTURE PHARMACOLOGICAL TREATMENT OPTIONS}

Recent developments in vasodilatory and antiproliferative approaches for the treatment of $\mathrm{PAH}$ have led to the ongoing clinical evaluation of new pharmacological compounds, with promising, albeit preliminary, results. These compounds include soluble guanylate cyclase agonists, platelet-derived growth factor-receptor antagonists, prostacyclin-receptor agonists and tyrosine kinase inhibitors. Clinical studies of these compounds are underway in adult patients with PAH. No data in paediatric $\mathrm{PAH}$ are available, but these compounds are expected to play a future role in paediatric PAH.

\section{NONPHARMACOLOGICAL THERAPIES}

According to the current treatment algorithm, atrial septostomy and/or lung transplantation should be considered in patients with inadequate response to maximal pharmacological therapy (level of evidence C) (fig. 1) [14].

Atrial septostomy may decompress the right heart and improve systemic cardiac output, albeit at the cost of hypoxaemia, and has been shown to relieve symptoms in a paediatric case series [76]. Patients with persistent syncope or with intractable right heart failure may benefit from this intervention. The procedure can be used as a bridge to lung transplantation. However, the effect of the procedure may be unpredictable, and its mortality is substantial (5-15\%) and seems to increase in patients with high right atrial pressures. The surgical creation of a Potts' shunt has been suggested as an alternative approach in patients with suprasystemic pulmonary vascular resistance [77]. However, the risk-benefit ratio of these procedures has not yet been established and optimal timing remains extremely
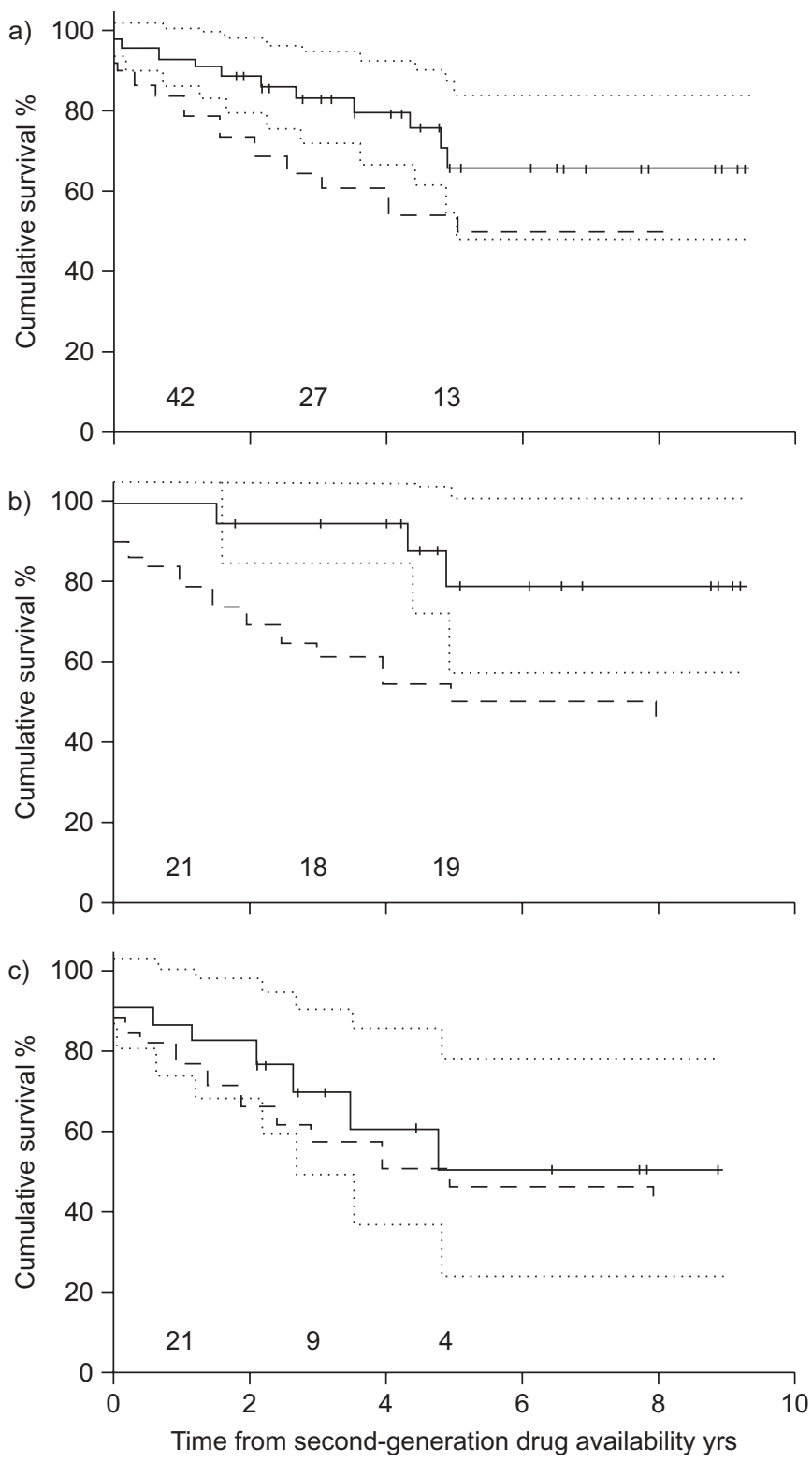

FIGURE 2. Observed survival (_- with $95 \%$ confidence intervals $(\cdots \cdots)$ and predicted survival using the National Institutes of Health registry equation $(----)$ from time of second-generation drug availability in a) patients for whom pulmonary arterial hypertension (PAH)-specific drugs became available during or before their diagnoses $(n=45)$, b) patients for whom PAH-specific drugs were not available at time of diagnosis but became available during the disease course $(n=21)$ and c) patients for whom second-generation drugs were available at time of diagnosis $(n=24)$. Reproduced from [13] with permission from the publisher.

difficult. For these reasons, they should only be conducted by centres with considerable experience of performing such procedures in children with PAH.

The decision to schedule a patient for lung (or heart-lung) transplantation should be based upon an assessment of prognosis, local donor availability and, thus, waiting time for transplantation and, finally, expected survival after transplantation. Median survival after lung transplantation in children 
is $4.3 \mathrm{yrs}$, with a tendency toward improved outcome in younger children ( $0-10$ yrs). The $3-$ and 5 -yr survival rates in children with heart-lung transplantation are $69 \%$ and $45 \%$, respectively [78].

\section{TREATMENT GOALS IN PAEDIATRIC PAH}

The response to treatment can be difficult to quantify in children. Additionally, it can be challenging to perform and interpret the traditional endpoints used in trials with adults such as the 6-min walk test, functional class and quality of life. The composite end-point of time to clinical worsening is gaining acceptance as a better indicator of clinical status and disease progression. However, this indicator needs a clear definition that may differ according to age or PAH aetiology in the paediatric population. The effectiveness of PAH therapies is increasingly being assessed through goal-oriented strategies in adult trials [75]. This seductive approach in which goals of treatment and follow-up procedures are predefined has not been applied to children but it could be used to tailor PAH therapy to individual patients. As proposed in the recent guidelines, regular evaluation of children with $\mathrm{PAH}$ should focus on variables with prognostic significance and treatment decisions should be based on parameters that are relevant for outcome [14]. In daily practice, clinical evaluation, exercise tests, biochemical markers, such as the N-terminal prohormone of brain natriuretic peptide, and echocardiographic assessments are required to have a clear picture of a child's condition [79]. It is also of note that decision making does not rely on a single parameter but on either their convergent or divergent results. Interpreting this composite information to guide therapy is a daily challenge in the management of children with PAH.

\section{CONCLUSIONS}

Despite several similarities, paediatric PAH has a distinct presentation compared with adult PAH. Not only are the conditions underlying PAH different in adults and children, with CHD far more predominant among paediatric patients, but the two populations are further distinguished by the presence of age-specific conditions that may be related to impaired lung development in children, including bronchopulmonary dysplasia or congenital diaphragmatic hernia. It becomes obvious, therefore, that paediatric $\mathrm{PAH}$ is a complex presentation that occurs among a heterogeneous group of patients and requires an extensive clinical work-up in order to appropriately define the aetiology in individual cases.

Examination of the current literature reveals limited data concerning the effect of treatments in paediatric $\mathrm{PAH}$, for both general therapies and those specific to the disease. However, those data that are available suggest that, in the short- to medium-term at least, treatment effects in children are comparable to those observed in adults.

The majority of prostanoid data is derived from studies of epoprostenol. In current guidelines this compound is recommended as a first-line treatment for patients with severe PAH (WHO FC IV) [14] and the literature confirms that paediatric use of epoprostenol is justified by its long-term functional and survival benefits, despite problems with continuous i.v. infusion. Recommendation of treprostinil is limited in children because of a lack of data and side-effects that include infusion site pain, although it may prove to be a useful switch therapy in cases of clinical deterioration or when an alternative to epoprostenol is required. The utility of inhaled iloprost in children is similarly limited by side-effects, but also by an inconvenient dosing schedule, but it may offer an alternative treatment option in selected paediatric cases. Insufficient data exist concerning oral beraprost in children, a situation that is unlikely to change given its low standing among experts. Of the ERAs, bosentan has been the most studied in the paediatric setting. Open-label studies in children have confirmed the positive efficacy and safety findings observed in adults, while demonstrating lower bosentan exposure in children in spite of increased doses. Uncontrolled data suggest that bosentan improves haemodynamic measures in children at short- and mid-term follow-up. However, data on longer term follow-up in children are more ambiguous and long-term deterioration of initial improvement in exercise capacity may be more prevalent in paediatric patients on monotherapy than in adults. A lack of data makes it difficult to assess the paediatric situation with regard to sitaxentan and ambrisentan.

In terms of the PDE5 inhibitors, only sildenafil has any paediatric data available. Open-label observational studies and preliminary results of a randomised, controlled trial appear to confirm the efficacy, safety and tolerability of sildenafil in paediatric patients with various forms of PAH.

According to current clinical guidelines, the adult PAH treatment algorithm should also be followed in paediatric patients, although this advice is a class IIa "weight of evidence" recommendation based on grade C "consensus of opinion" evidence [14]. Review of published data and current paediatric expert opinions support that advice; however, in order to provide clinicians with more robust recommendations based on firm experimental evidence, randomised, controlled clinical trials of $\mathrm{PAH}$ treatments in the paediatric setting are necessary. In particular, although not exclusively, safety studies, pharmacokinetic investigations and studies of treatment in PAH patients with age-specific conditions, including bronchopulmonary dysplasia, congenital diaphragmatic hernia or trisomy 21 , would provide a useful widening of the evidence base in paediatric PAH.

Due to its progressive and devastating nature, the prognosis of paediatric PAH remains a serious concern. A plethora of pharmaceutical treatments options are on the horizon, which may offer increased hope in the future; but until then, timely treatment and early combination therapy may be the best courses of action to improve survival in childhood $\mathrm{PAH}$.

\section{STATEMENT OF INTEREST}

R.M.F. Berger has served on advisory boards of Actelion Pharmaceuticals, GlaxoSmithKline and Eli Lilly, and received research grants from Actelion Pharmaceuticals. D. Bonnet has received fees for speaking from Actelion Pharmaceuticals.

\section{ACKNOWLEDGEMENTS}

This article is based on a PH Forum held in April 2010 that was sponsored by Actelion Pharmaceuticals Ltd (Allschwil, Switzerland). The authors received minor editorial assistance from L. Thomas, 
Elements Communications Ltd (Westerham, UK) and did not benefit financially from the sponsorship of this series of articles. The sponsors of the forum were not directly involved in the writing of this article.

\section{REFERENCES}

1 Wagenvoort C, Wagenvoort N. Primary pulmonary hypertension: a pathologic study of the lung vessels in 156 clinically diagnosed cases. Circulation 1970; 42: 1163-1184.

2 Humbert M, Morrell NW, Archer SL, et al. Cellular and molecular pathobiology of pulmonary arterial hypertension. J Am Coll Cardiol 2004; 43: Suppl. S, 13S-24S.

3 Rosenzweig EB, Morse JH, Knowles JA, et al. Clinical implications of determining BMPR2 mutation status in a large cohort of children and adults with pulmonary arterial hypertension. J Heart Lung Transplant 2008; 27: 668-674.

4 van Loon RL, Roofthooft MT, van Osch-Gevers M, et al. Clinical characterization of pediatric pulmonary hypertension: complex presentation and diagnosis. J Pediatr 2009; 155: 176-182.

5 Moledina S, Hislop AA, Foster H, et al. Childhood idiopathic pulmonary arterial hypertension: a national cohort study. Heart 2010; 96: 1401-1406.

6 Beghetti M, Hoeper MM, Kiely DG, et al. Safety experience with bosentan in 146 children 2-11 years old with pulmonary arterial hypertension: results from the European Postmarketing Surveillance program. Pediatr Res 2008; 64: 200-204.

7 Humbert M, Sitbon O, Chaouat A, et al. Pulmonary arterial hypertension in France: results from a national registry. Am J Respir Crit Care Med 2006; 173: 1023-1030.

8 Berger RM. Possibilities and impossibilities in the evaluation of pulmonary vascular disease in congenital heart defects. Eur Heart J 2000; 21: 17-27.

9 Haworth SG, Hislop AA. Treatment and survival in children with pulmonary arterial hypertension: The UK Pulmonary Hypertension Service for Children 2001-2006. Heart 2009; 95: 312-317.

10 Simonneau G, Robbins IM, Beghetti M, et al. Updated clinical classification of pulmonary hypertension. J Am Coll Cardiol 2009; 54: Suppl. 1, S43-S54.

11 Abman SH. Recent advances in the pathogenesis and treatment of persistent pulmonary hypertension of the newborn. Neonatology 2007; 91: 283-290.

12 D'Alonzo GE, Barst RJ, Ayres SM, et al. Survival in patients with primary pulmonary hypertension. Results from a national prospective registry. Ann Intern Med 1991; 115: 343-349.

13 van Loon RL, Roofthooft MT, Delhaas T, et al. Outcome of pediatric patients with pulmonary arterial hypertension in the era of new medical therapies. Am J Cardiol 2010; 106: 117-124.

14 Galiè N, Hoeper MM, Humbert M, et al. Guidelines for the diagnosis and treatment of pulmonary hypertension: The Task Force for the Diagnosis and Treatment of Pulmonary Hypertension of the European Society of Cardiology (ESC) and the European Respiratory Society (ERS), endorsed by the International Society of Heart and Lung Transplantation (ISHLT). Eur Heart J 2009; 30: 2493-2537.

15 Bowyer JJ, Busst CM, Denison DM, et al. Effect of long term oxygen treatment at home in children with pulmonary vascular disease. Br Heart J 1986; 55: 385-390.

16 Sandoval J, Aguirre JS, Pulido T, et al. Nocturnal oxygen therapy in patients with the Eisenmenger syndrome. Am J Respir Crit Care Med 2001; 164: 1682-1687.

17 Fuster V, Steele PM, Edwards WD, et al. Primary pulmonary hypertension: natural history and the importance of thrombosis. Circulation 1984; 70: 580-587.
18 Donti A, Formigari R, Ragni L, et al. Pulmonary arterial hypertension in the pediatric age. J Cardiovasc Med 2007; 8: 72-77.

19 Daliento L, Somerville J, Presbitero P, et al. Eisenmenger syndrome: factors relating to deterioration and death. Eur Heart $J$ 1998; 19: 1845-1855.

20 Ekert H, Gilchrist GS, Stanton R, et al. Hemostasis in cyanotic congenital heart disease. J Pediatr 1970; 76: 221-230.

21 Maurer HM, McCue CM, Robertson LW, et al. Correction of platelet dysfunction and bleeding in cyanotic congenital heart disease by simple red cell volume reduction. Am J Cardiol 1975; 35: 831-835.

22 Rashid A, Ivy D. Severe paediatric pulmonary hypertension: new management strategies. Arch Dis Child 2005; 90: 92-98.

23 Young G. New anticoagulants in children. Hematol Am Soc Hematol Educ Program 2008; 2008: 245-250.

24 Tulloh R, Marsh M, Blackburn M, et al. Recommendations for the use of palivizumab as prophylaxis against respiratory syncytial virus in infants with congenital cardiac disease. Cardiol Young 2003; 13: 420-423.

25 Haworth SG. The management of pulmonary hypertension in children. Arch Dis Child 2008; 93: 620-625.

26 Rich S, Kaufmann E, Levy PS. The effect of high doses of calciumchannel blockers on survival in primary pulmonary hypertension. N Engl J Med 1992; 327: 76-81.

27 Barst RJ, Maislin G, Fishman AP. Vasodilator therapy for primary pulmonary hypertension in children. Circulation 1999; 99: 11971208.

28 Sitbon $\mathrm{O}$, Humbert $\mathrm{M}$, Jais $\mathrm{X}$, et al. Long-term response to calcium channel blockers in idiopathic pulmonary arterial hypertension. Circulation 2005; 111: 3105-3111.

29 Tuder RM, Cool CD, Geraci MW, et al. Prostacyclin synthase expression is decreased in lungs from patients with severe pulmonary hypertension. Am J Respir Crit Care Med 1999; 159: 1925-1932.

30 Christman BW, McPherson CD, Newman JH, et al. An imbalance between the excretion of thromboxane and prostacyclin metabolites in pulmonary hypertension. N Engl J Med 1992; 327: 70-75.

31 Barst RJ, Rubin LJ, Long WA, et al. A comparison of continuous intravenous epoprostenol (prostacyclin) with conventional therapy for primary pulmonary hypertension. The Primary Pulmonary Hypertension Study Group. N Engl J Med 1996; 334: 296-302.

32 Lammers AE, Hislop AA, Flynn Y, et al. Epoprostenol treatment in children with severe pulmonary hypertension. Heart 2007; 93 739-743.

33 Yung D, Widlitz AC, Rosenzweig EB, et al. Outcomes in children with idiopathic pulmonary arterial hypertension. Circulation 2004 110: $660-655$.

34 Laliberte K, Arneson C, Jeffs R, et al. Pharmacokinetics and steadystate bioequivalence of treprostinil sodium (Remodulin) administered by the intravenous and subcutaneous route to normal volunteers. J Cardiovasc Pharmacol 2004; 44: 209-214.

35 Voswinckel R, Enke B, Reichenberger F, et al. Favorable effects of inhaled treprostinil in severe pulmonary hypertension: results from randomized controlled pilot studies. Ann Intern Med 2006; 144: 149-150.

36 Simonneau G, Barst RJ, Galiè N, et al. Continuous subcutaneous infusion of treprostinil, a prostacyclin analogue, in patients with pulmonary arterial hypertension: a double-blind, randomized, placebo-controlled trial. Am J Respir Crit Care Med 2002; 165: 800-804.

37 Oudiz RJ, Schilz RJ, Barst RJ, et al. Treprostinil, a prostacyclin analogue, in pulmonary arterial hypertension associated with connective tissue disease. Chest 2004; 126: 420-427.

38 Tapson VF, Gomberg-Maitland M, McLaughlin VV, et al. Safety and efficacy of IV treprostinil for pulmonary arterial hypertension: 
a prospective, multicenter, open-label, 12-week trial. Chest 2006; 129: 683-688.

39 Levy M, Bajolle F, Cohen S, et al. Subcutaneous treprostinil: a new therapeutic approach for idiopathic paediatric pulmonary hypertension. Eur Respir J 2009; 34: Suppl. 53, 258 S.

40 Ivy DD, Claussen L, Doran A. Transition of stable pediatric patients with pulmonary arterial hypertension from intravenous epoprostenol to intravenous treprostinil. Am J Cardiol 2007; 99: 696-698.

41 McLaughlin VV, Benza RL, Rubin LJ, et al. Addition of inhaled treprostinil to oral therapy for pulmonary arterial hypertension: a randomized controlled clinical trial. J Am Coll Cardiol 2010; 55: 19; $15-22$.

42 Fitscha P, Tiso B, Krais T, et al. Effect of iloprost on in vivo and in vitro platelet function in patients with peripheral vascular disease (PVD). Adv Prostaglandin Thromboxane Leukot Res 1987; 17A 450-454.

43 Olschewski H, Simonneau G, Galiè N, et al. Inhaled iloprost for severe pulmonary hypertension. N Engl J Med 2002 1, 347: 322-329.

44 Ivy DD, Doran AK, Smith KJ, et al. Short- and long-term effects of inhaled iloprost therapy in children with pulmonary arterial hypertension. J Am Coll Cardiol 2008 15, 51: 161-169.

45 Galiè N, Humbert M, Vachiéry JL, et al. Effects of beraprost sodium, an oral prostacyclin analogue, in patients with pulmonary arterial hypertension: a randomized, double-blind, placebo-controlled trial. J Am Coll Cardiol 2002; 39: 1496-1502.

46 Barst RJ, McGoon M, McLaughlin V, et al. Beraprost therapy for pulmonary arterial hypertension. J Am Coll Cardiol 2003; 41: $2119-2125$.

47 Gregan B, Jurgensen J, Papsdorf G, et al. Ligand-dependent differences in the internalization of endothelin A and endothelin B receptor heterodimers. J Biol Chem 2004; 279: 27679-27687.

48 Channick RN, Simonneau G, Sitbon O, et al. Effects of the dual endothelin-receptor antagonist bosentan in patients with pulmonary hypertension: a randomised placebo-controlled study. Lancet 2001; 358: 1119-1123.

49 Rubin LJ, Badesch DB, Barst RJ, et al. Bosentan therapy for pulmonary arterial hypertension. N Engl I Med 2002; 346: 896-903.

50 Galiè N, Rubin LJ, Hoeper M, et al. Treatment of patients with mildly symptomatic pulmonary arterial hypertension with bosentan (EARLY study): a double-blind, randomised controlled trial. Lancet 2008; 371: 2093-2100.

51 Galiè N, Beghetti M, Gatzoulis MA, et al. Bosentan therapy in patients with Eisenmenger syndrome: a multicenter, double-blind, randomized, placebo-controlled study. Circulation 2006; 114 48-54.

52 Gatzoulis MA, Beghetti M, Galiè N, et al. Longer-term bosentan therapy improves functional capacity in Eisenmenger syndrome: results of the BREATHE- 5 open-label extension study. Int J Cardiol 2008; 127: 27-32

53 Barst RJ, Ivy D, Dingemanse J, et al. Pharmacokinetics, safety, and efficacy of bosentan in pediatric patients with pulmonary arterial hypertension. Clin Pharmacol Ther 2003; 73: 372-382.

54 Beghetti M, Haworth SG, Bonnet D, et al. Pharmacokinetic and clinical profile of a novel formulation of bosentan in children with pulmonary arterial hypertension: the FUTURE-1 study. Br J Clin Pharmacol 2009; 68: 948-955.

55 Rosenzweig EB, Ivy DD, Widlitz A, et al. Effects of long-term bosentan in children with pulmonary arterial hypertension. J Am Coll Cardiol 2005; 46: 697-704

56 Simpson CM, Penny DJ, Cochrane AD, et al. Preliminary experience with bosentan as initial therapy in childhood idiopathic pulmonary arterial hypertension. J Heart Lung Transplant 2006; 25: 469-473.
57 van Loon RL, Hoendermis ES, Duffels MG, et al. Long-term effect of bosentan in adults versus children with pulmonary arterial hypertension associated with systemic-to-pulmonary shunt: does the beneficial effect persist? Am Heart J 2007; 154 776-782.

58 Barst RJ, Langleben D, Frost A, et al. Sitaxsentan therapy for pulmonary arterial hypertension. Am J Respir Crit Care Med 2004 169: 441-447.

59 Barst RJ, Langleben D, Badesch D, et al. Treatment of pulmonary arterial hypertension with the selective endothelin-A receptor antagonist sitaxsentan. J Am Coll Cardiol 2006; 47: 2049-2056.

60 Benza RL, Barst RJ, Galie N, et al. Sitaxsentan for the treatment of pulmonary arterial hypertension: a 1-year, prospective, open-label observation of outcome and survival. Chest 2008, 134: 775-782.

61 Barst RJ, Rich S, Widlitz A, et al. Clinical efficacy of sitaxsentan, an endothelin-A receptor antagonist, in patients with pulmonary arterial hypertension: open-label pilot study. Chest 2002; 121 1860-1868.

62 Galiè N, Olschewski H, Oudiz RJ, et al. Ambrisentan for the treatment of pulmonary arterial hypertension: results of the ambrisentan in pulmonary arterial hypertension, randomized, double-blind, placebo-controlled, multicenter, efficacy (ARIES) study 1 and 2. Circulation 2008; 117: 3010-3019.

63 Galié N, Badesch D, Oudiz R, et al. Ambrisentan therapy for pulmonary arterial hypertension. J Am Coll Cardiol 2005; 46 529-535.

64 Wharton J, Strange JW, Møller GM, et al. Antiproliferative effects of phosphodiesterase type 5 inhibition in human pulmonary artery cells. Am J Respir Crit Care Med 2005; 172: 105-113.

65 Tantini B, Manes A, Fiumana E, et al. Antiproliferative effect of sildenafil on human pulmonary artery smooth muscle cells. Basic Res Cardiol 2005; 100: 131-138.

66 Galie N, Ghofrani HA, Torbicki A, et al. Sildenafil citrate therapy for pulmonary arterial hypertension. N Engl I Med 2005; 353: 2148-2157.

67 Galie N, Brundage BH, Ghofrani HA, et al. Tadalafil therapy for pulmonary arterial hypertension. Circulation 2009; 119: 2894-2903.

68 Humpl T, Reyes JT, Holtby $\mathrm{H}$, et al. Beneficial effect of oral sildenafil therapy on childhood pulmonary arterial hypertension: twelve-month clinical trial of a single-drug, open-label, pilot study. Circulation 2005; 111: 3274-3280.

69 Barst R, Richardson H, Konourina I, et al. Oral sildenafil treatment in children with pulmonary arterial hypertension $(\mathrm{PAH})$ : results of a double-blind, placebo-controlled, dose-ranging study. Eur Respir J 2009; 34: Suppl. 53, 3s.

70 Stocker C, Penny DJ, Brizard CP, et al. Intravenous sildenafil and inhaled nitric oxide: a randomised trial in infants after cardiac surgery. Intensive Care Med 2003; 29: 1996-2003.

71 Schulze-Neick I, Hartenstein P, Li J, et al. Intravenous sildenafil is a potent pulmonary vasodilator in children with congenital heart disease. Circulation 2003; 108: Suppl. 1, II: 167-173.

72 Akagi S, Matsubara H, Miyaji K, et al. Additional effects of bosentan in patients with idiopathic pulmonary arterial hypertension already treated with high-dose epoprostenol. Circ J 2008; 72: 114-116.

73 Simonneau G, Rubin LJ, Galiè N, et al. Addition of sildenafil to long-term intravenous epoprostenol therapy in patients with pulmonary arterial hypertension: a randomized trial. Ann Intern Med 2008; 149: 521-530

74 Channick RN, Olschewski H, Seeger W, et al. Safety and efficacy of inhaled treprostinil as add-on therapy to bosentan in pulmonary arterial hypertension. J Am Coll Cardiol 2006; 48: 1433-1437. 
75 Hoeper MM, Markevych I, Spiekerkoetter E, et al. Goal-oriented treatment and combination therapy for pulmonary arterial hypertension. Eur Respir J 2005; 26: 858-863.

76 Micheletti A, Hislop AA, Lammers A, et al. Role of atrial septostomy in the treatment of children with pulmonary arterial hypertension. Heart 2006; 92: 969-972.

77 Blanc J, Vouhe P, Bonnet D. Potts shunt in patients with pulmonary hypertension. N Engl J Med 2004; 350: 623.
78 Aurora P, Edwards LB, Christie JD, et al. Registry of the International Society for Heart and Lung Transplantation: Twelfth Official Pediatric Lung and Heart/Lung Transplantation Report - 2009. J Heart Lung Transplant 2010; 28: 1129-1141.

79 Bernus A, Wagner BD, Accurso F, et al. Brain natriuretic peptide levels in managing pediatric patients with pulmonary arterial hypertension. Chest 2009; 135: 745-751. 